\author{
ANNA MAŃKOWSKA* \\ Poznań, Polska \\ ORCID ID oooo-0003-1026-9487
}

\title{
KIERUNKI UMIĘDZYNARODOWIENIA EDUKACJI WYŻSZEJ W CHINACH
}

\begin{abstract}
Streszczenie: Celem podjętych analiz jest omówienie współczesnych kierunków i trendów w umiędzynarodowieniu edukacji wyższej w Chinach. Przedmiotem badań jest zjawisko umiędzynarodowienia na poziomie edukacji wyższej - instytucjonalne rozwiązania oraz praktyczne implikacje. Opisane zostały krajowe programy usprawniania przepływu wiedzy, migracje studentów chińskich, tworzenie transnarodowych uczelni wyższych oraz polityka zatrudniania międzynarodowej kadry akademickiej. W treści artykułu wykorzystano badania zastane chińskich i zagranicznych autorów. Jako metodę badawczą wybrano analizę źródeł wtórnych.
\end{abstract}

Słowa kluczowe: umiędzynarodowienie edukacji, westernizacja edukacji, edukacja wyższa, Chiny, globalizacja.

\section{Wstęp}

Proces umiędzynarodowienia edukacji wyższej jest zjawiskiem powszechnie znanym na całym świecie. W przypadku Chin można mówić o blisko 50-letniej tradycji. Początki pierwszych działań, które sięgały tradycji umiędzynarodowienia w Chinach, przypadają na lata 70., a w ostatnim czasie nastąpiła intensyfikacja zjawiska (Mańkowska 2020). Zdaniem Rui Yang (2016), umiędzynarodowienie w chińskiej ramie obejmuje kilka obszarów: podejmowanie studiów za granicą przez studentów z Chin, zapożyczanie międzynarodowych standardów nauczania i uczenia się oraz tworzenie fuzji uniwersyteckich pomiędzy Chinami a wybranymi krajami. W trwającym prawie 50 lat procesie wdrażania umiędzynarodowienia edukacji można odnaleźć wiele napięć, rozwiązań czasowych (przejściowych)

* Anna Mańkowska, adiunkt, Pracownia Pedagogiki Porównawczej, Wydział Studiów Edukacyjnych, Uniwersytet im. Adama Mickiewicza w Poznaniu; e-mail: anna.mankowska@ amu.edu.pl. 
oraz takich, które inspirowane zachodnimi trendami nie zawsze wpisywały się w chiński kontekst i tradycję, dlatego jedno z głównych pytań, na które będę próbowała odpowiedzieć, brzmi: czy chińskie umiędzynarodowienie edukacji wyższej nie jest bliższe westernizacji edukacji? Czy Chinom udało się zachować tradycję i kulturę w tym globalnym procesie edukacji? W niniejszym artykule czytelnik odnajdzie teoretyczne rozważania nad zjawiskiem umiędzynarodowienia edukacji wyższej w Chinach. Przedstawiam wybrane, moim zdaniem, kluczowe przykłady strategii wdrażania polityki umiędzynarodowienia edukacji wyżej oraz omawiam doświadczenia chińskich studentów, którzy uczestniczą w procesie umiędzynarodowienia. Kluczem wyboru praktyk były priorytety wymienione w rządowym planie rozwoju edukacji pt. Outline of China's Medium and Long-Term Plan for Education Reform and Development (2010-2020). Za metodę badawczą przyjęłam metodę analizy badań zastanych oraz wspomnianego dokumentu, gdyż dzięki nim miałam dostęp do danych już opracowanych (opublikowanych artykułów). Ponadto $\mathrm{w}$ artykule wykorzystuję informacje zdobyte w trakcie udziału w międzynarodowym projekcie badawczym dotyczącym umiędzynarodowienia edukacji w krajach Nowego Jedwabnego Szlaku, „The International Cooperation and Exchange Policy for Education in Belt and Road Countries", w którym brałam udział w latach 2016-2020. Oddawany do rąk czytelnika artykuł jest wstępem i jednocześnie zaproszeniem do analizy oraz zgłębiania zagadnienia umiędzynarodowienia edukacji wyższej w Chinach.

\section{Umiędzynarodowienie edukacji - interpretacja zjawiska}

Zjawisko umiędzynarodowienia edukacji - z języka angielskiego internationalisation of higher education (IoHE), wymaga uściślenia terminologicznego. Shibao Guo i Mackie Chase (2011) są przekonani, że umiędzynarodowienie edukacji odnosi się głównie do oraz przejawia w mobilności edukacyjnej studentów, międzynarodowych partnerstwach w projektach i programach akademickich. Z kolei Hans de Wit, Fiona Hunter, Laura Howard oraz Eva Egron-Polak (2015), w obszernym opracowaniu Parlamentu Europejskiego podają, że umiędzynarodowienie to zamierzony proces integrowania międzynarodowych, międzykulturowych lub globalnych wymiarów w celu realizacji edukacji po szkole średniej, z uwzględnieniem faktu, że współcześnie obejmuje ona także kredytowanie przedmiotów (np. obejmowanie punktami ECTS), mobilność studencką, wymianę akademicką, poszukiwanie globalnych talentów, opracowywanie międzynarodowych programów nauczania i efektów uczenia się, działalność franczyzową uniwersytetów i szkół wyższych, współpracę oraz rywalizację akademicką. W literaturze przedmiotu możemy odnaleźć także krytyczne głosy badaczy w kontekście umiędzynarodowienia edukacji wyższej. Allan Luke (2010) określa je jako złożony, chaotyczny i nieprzewidywalny „edubiznes”, który priorytetowo traktuje finanse oraz wypiera jasne, normatywne i ideologiczne intencje edukacji. Zauważyć można także, że od 
lat 90. procesy umiędzynarodowienia edukacji są dodatkowo napędzane przez siły neoliberalne, kierujące się motywami ekonomicznymi. W wielu miejscach na świecie, np. w Kanadzie, Australii, Wielkiej Brytanii czy Stanach Zjednoczonych, gdzie umiędzynarodowienie edukacji wyższej ma wieloletnią tradycję, studenci zagraniczni są wykorzystywani do generowania przychodów uczelni (de Wit i in. 2015).

Zdaniem de Wit, Hunter, Howard oraz Egron-Polak (2015), na zjawisko umiędzynarodowienia można spojrzeć dwojako: z perspektywy globalnej i lokalnej. Globalna interpretacja zakłada umiędzynarodowienie procedur, praw oraz programów szkolnictwa wyższego. Perspektywa ta obejmuje wszystkie praktyczne działania i akcje, takie jak: mobilność studentów, międzynarodowe projekty oraz programy. Perspektywa lokalna jest zorientowana na programy nauczania i skupia się na czynnościach, które rozwijają międzynarodowe oraz międzykulturowe umiejętności. Uważam jednak, że rozróżnienie zaproponowane przez autorów nie jest wyczerpujące, gdyż strategie globalne także są zorientowane na kształcenie międzynarodowych kompetencji.

\section{Chińskie umiędzynarodowienie edukacji}

Umiędzynarodowienie edukacji wyższej jest niezwykle interesujące na gruncie porównawczym, a w Europie i Azji przybiera inne oblicze. W Chinach zaś, ze względu na politykę oraz kulturę, przebiegało jeszcze inaczej. Po kilku dekadach reform ekonomicznych i otwieraniu polityki dopiero od roku 1978 Chiny dokładają wszelkich starań, aby tworzyć światowej klasy uniwersytety oraz korzystać z bogatej, wielowiekowej tradycji europejskiej. Aczkolwiek literatura podaje, że pierwszy amerykański uniwersytet w Chinach został otwarty w Szanghaju w roku 1879 Shanghai Saint John's University (1879-1952) i jest przykładem wczesnego umiędzynarodowienia edukacji w tym państwie. Po roku 1949, kiedy Chiny przystąpiły do współpracy ze Związkiem Radzieckim oraz Wschodnią Europą, w akademicką rzeczywistość zostały wdrożone pierwsze akademickie współprace i wyjazdy. Obecnie umiędzynarodowienie edukacji wyższej jest częścią strategicznego planu rozwojowego w Państwie Środka o nazwie Outline of China's Medium and LongTerm Plan for Education Reform and Development, według którego reformowane uniwersytety są zobowiązane do wprowadzania różnego rodzaju strategii i działań.

W Chinach wdrożono kilka programów, które mają na celu rozwój umiędzynarodowienia edukacji poprzez wykorzystanie świata wirtualnego i szeroko pojętej technologii IT. Pierwszym z nich jest narodowy program rządowy o nazwie Internet + Action Plan, który obejmuje budowę przemysłowej infrastruktury internetowej we wszystkich regionach i branżach, w tym edukacyjnej, obejmujących 10 kluczowych sektorów przemysłu. Projekt będzie ukończony do 2023 roku. Rząd ma nadzieję, że utworzy od trzech do pięciu przemysłowych platform internetowych o międzynarodowym wpływie, oprócz krajowego centrum powstanie mechanizm 
przemysłowej wymiany Internetu i współpracy z Unią Europejską oraz głównymi krajami w inicjatywie Pasa i Szlaku (OBOR). W kontekście edukacji nowa technologia umożliwi naukę na odległość, a także pozwoli na lepsze funkcjonowanie oraz wykorzystanie instytucji uniwersytetu otwartego. Światowe uniwersytety i systemy edukacyjne będą mogły dołączyć do chińskiej hiperłączności edukacyjnej na określonych warunkach oraz zasadach.

Za kolejne celowe kroki w stronę umiędzynarodowienia edukacji wyższej w chińskim kontekście należy uznać jednostronne migracje studentów (Mańkowska 2017). Badacze Baocun Liu i Qiang Liu (2016) twierdzą, że współcześnie mobilność studentów między Chinami a resztą świata pozostaje centralnym punktem umiędzynarodowienia. Warto $\mathrm{w}$ tym miejscu dodać, że chińscy studenci od zawsze byli obecni w akademickiej rzeczywistości wielu uniwersytetów na świecie, a po powrocie mieli swoją wiedzą przyczyniać się do budowania lepszego ładu w kraju. Przykładem osobowości, które doświadczyły migracji edukacyjnych, są: Ma Yinchu, student Uniwersytetu Yale oraz Columbii, autor polityki jednego dziecka, a także sam Deng Xiaoping, przywódca Chińskiej Republiki Ludowej w latach 1978-1989. Chiny początkowo wysyłały wybranych studentów w określone rejony świata, m.in. do Związku Radzieckiego oraz innych socjalistycznych krajów, aby studiowali zaawansowane nauki technologiczne i zarządzanie. Do lat 6o. wyjazdy na studia były zarezerwowane dla wąskiej grupy osób. Współcześnie rząd chiński określił warunki dla naukowców i studentów przebywających za granicą oraz deklarujących chęć wyjazdu. Transfery zagraniczne, jeżeli chodzi o przepływ studentów i kadry naukowej, podlegają w Chinach ścisłej kontroli urzędniczej. Z każdym kandydatem, który wyraża chęć wyjazdu za granicę, przeprowadza się rozmowę, aby poznać motywy podróży oraz perspektywy jego powrotu. Nie można jednoznacznie stwierdzić, że urzędnicy mogą stanowić przeszkodę w migracji edukacyjnej, ale kandydat na pewno musi spełnić szereg wygórowanych wymagań i udowodnić swoją motywację (determinację), a także możliwości finansowe do podjęcia edukacji za granicą. Do 2017 roku w krajach Organizacji Współpracy Gospodarczej i Rozwoju (OECD) liczba zapisów chińskich studentów na zagraniczne studia wyższe wyniosła 23 proc. (860 tys.) (OECD 2019). Chiński rząd mocno zachęca uniwersytety do angażowania się w rozwój transnarodowych programów wymiany w celu wzmocnienia i przyspieszenia procesów umiędzynarodowienia szkolnictwa wyższego.

Przystąpienie Chin do Światowej Organizacji Handlu w 2001 roku otworzyło nowe ścieżki do umiędzynarodowienia edukacji wyższej i wyznaczyło kolejne inspiracje. Chiny zaczęły angażować się w umiędzynarodowienie szkolnictwa wyższego poprzez tworzenie oraz rozwój tzw. CFCRS (Chinese Foreign Cooperative Running School). Są to uniwersytety będące transnarodowymi instytucjami szkolnictwa wyższego (transnational higher education - TNHE), które stanowią kolejny kluczowy element strategii współczesnego umiędzynarodowienia edukacji wyższej w Państwie Środka. Edukacja transnarodowa (TNHE) jest powszechnie akceptowanym i używanym terminem opisującym przepływ usług edukacyjnych 
między krajami w codziennych zastosowaniach badawczych. To swego rodzaju hybryda edukacyjna, gdzie w przypadku Chin wypracowano kilka sposobów funkcjonowania tego typu edukacji, takich jak niezależne instytucje czy łączone programy studiów. W szczególności jest to program w modelu na przykład $2+2$, który umożliwia studiowanie $\mathrm{w}$ dwóch systemach edukacji $\mathrm{w}$ ramach jednego programu studiów licencjackich przez dwa lata w każdym kraju, albo programy w układach: $1+1,3+1$ lub $4+0$. Ten rodzaj studiów jest w Chinach powszechny i stanowi odpowiedź chińskich uniwersytetów na zainteresowanie obywateli uzyskaniem dualnego dyplomu (Hu, Willis 2016). Zjawisko jest na tyle nowe, że w literaturze przedmiotu odnajdujemy nieliczne prace, które pokazały doświadczenia edukacyjne Chińczyków ze studiów CFCRS (Qin i in. 2016; Trahar 2015; Wang $i$ in. 2016). Istniejące badania zastane pokazują, że uczenie się oraz nauczanie na studiach CFCRS jest zjawiskiem złożonym zarówno dla studentów, jak i nauczycieli akademickich. Fang Wang, Anthony Clarke oraz Wei Yu (2016) w przeprowadzonych badaniach nad doświadczeniami studentów z rzeczonego programu na linii Chiny-Kanada pokazali, że główne wyzwania mariażu polegały na doświadczaniu międzykulturowego uczenia się (różnice językowe, kompetencje językowe, relacje studenckie czy podejście do uczenia się i do wiedzy ogólnie). Z kolei Josephine Ng oraz Berenice Nyland (2016), badając wykładowców, zauważyli, że najczęściej pojawiającymi się trudnościami były: nieefektywna komunikacja dotyczącą zagadnień nauczania i mała interakcja pomiędzy australijskimi oraz chińskimi wykładowcami. Inne badania pokazały, że przy małym zaangażowaniu uniwersytetów goszczących, np. wobec braku programów wprowadzających w kulturę kraju przyjmującego, studenci z Chin napotykali szereg problemów dotyczących niedostosowania kulturowego i licznych nieporozumień wynikających z tego tytułu (Yang, Lesser 2017).

Następną strategią wdrażania procesów umiędzynarodowienia edukacji jest zatrudnianie zagranicznej kadry na uniwersytetach chińskich i wprowadzanie dla studentów zajęć w języku angielskim. Działania te mają na celu rozwijanie kompetencji młodych Chińczyków oraz przygotowywanie ich do korzystania z możliwości, jakie stwarza umiędzynarodowienie, m.in. do mobilności studenckiej. Innym przykładem działań jest wprowadzanie do sylabusów przedmiotów obowiązkowej, zatwierdzonej anglojęzycznej literatury, co z jednej strony jest krokiem w stronę umiędzynarodowienia edukacji, a $\mathrm{z}$ drugiej rozwiązaniem wspierającym westernizację edukacji w Chinach (Guo i in. 2021).

Rui Yang (2016) w swoich badaniach nad reformami szkolnictwa wyższego w Chinach udowadnia, że współczesne zmiany są mocno inspirowane Zachodem, głównie amerykańskimi modelami edukacji, administracji i - co gorsza - ewaluacji. Większość chińskich reform szkolnictwa wyższego pochodzi z inspiracji zachodnich, co przejawia się chociażby w wymianach międzynarodowych oraz różnego rodzaju współpracach. Trudne jest to do zaakceptowania i wdrożenia w kraju o bardzo odmiennej historii oraz tradycji kulturowej. Warto w tym miejscu 
powołać się na wyniki badań Guo oraz współpracowników (2021), którzy na podstawie przeprowadzonych wywiadów ze studentami dokonali analizy zjawiska. Konkluzje z badań tych autorów pokazują, że chińscy studenci są świadomi procesów umiędzynarodowienia edukacji. W swoich wypowiedziach zwracają uwagę na fakt, że Chiny podejmują mariaże edukacyjne głównie z krajami anglojęzycznymi, wysoko rozwiniętymi, takimi jak Stany Zjednoczone, Kanada, Australia czy Wielka Brytania. Twierdzą, że umiędzynarodowienie edukacji jest jednokierunkowe. Ciekawy wniosek płynący z przeprowadzonych badań dotyczy pozycji literatury anglojęzycznej w czasie studiów. Badani studenci przyznawali, że literaturę autorstwa zagranicznych badaczy podświadomie uznają za bardziej wartościową aniżeli literaturę i materiały chińskich autorów. Studenci podkreślali, że język angielski zdominował nauki społeczne oraz ścisłe, że wiedza lokalna jest dewaluowana przez „angielskie wnioski i spostrzeżenia”, a główne nurty oraz prądy w naukach ulegają westernizacji. Zachodnia perspektywa wydaje się tak kluczowa, że całe przedmioty nauczania są budowane na zachodnich normach i literaturze. Organizowane konferencje, choć odbywają się w Chinach i goszczą uczestników porozumiewających się w języku chińskim, „dzieją się” po angielsku, co dla studentów o zróżnicowanym poziomie znajomości języka angielskiego nie zawsze jest łatwe i dostępne. Opisane zjawiska są efektem zachodniej supremacji reprodukowanej nie tylko Chinach, lecz także na całym świecie (Stein, Andreotti 2016). Badani studenci podkreślali także, że umiędzynarodowienie nie jest pisane wszystkim, gdyż aby wziąć udział w studiach typu CFCRS, prócz dobrej znajomości i wysokich wyników w testach z języka angielskiego trzeba jeszcze mieć odpowiednie zasoby finansowe, które umożliwią utrzymanie się za granicą.

\section{Zakończenie}

Współczesne Chiny są mieszanką wschodnich i zachodnich idei. Praktycznie niemożliwe jest oddzielenie Chińczyków od Zachodu na wszystkich poziomach wartości, instytucji społecznych oraz materiałów. Trudno jednoznacznie stwierdzić, czy umiędzynarodowienie edukacji wyższej w Chinach jest zastępowane procesem westernizacji edukacji. Warto zaryzykować stwierdzenie, że jest częścią większego, globalnego procesu, a westernizacja to pewnego rodzaju narzędzie, które prowadzi do celu. W moim przekonaniu Chiny w rozwiązaniach edukacyjnych podjęły wyzwanie wdrożenia zachodnich idei, a co więcej, nauczyły się na nie reagować. Bez wymiany i przemieszczania się wiedzy oraz idei ani rozwój narodowy, ani indywidualny nie byłby możliwy w żadnym społeczeństwie. Nie jest także konstruktywne narzekanie na westernizację różnych dziedzin życia, w tym edukacji. Realistyczne podejście polega na znalezieniu nowych sposobów. Sądzę, że współistnienie idei ma istotne implikacje pojęciowe i epistemologiczne dla wzajemnego oddziaływania tradycji intelektualnych oraz praktyk edukacyjnych, a zadaniem badaczy oraz praktyków edukacyjnych jest oddzielnie „ziarna od plew”, czy - jak 
mawiał Mao - „odcinanie wyrafinowanego od surowego”. Przedstawiona chińska perspektywa pokazuje, że Państwo Środka inspiruje się rozwiązaniami zachodnimi, a studenci bezpośrednio odczuwają tego skutki i potrafią rozpoznać zachodzące zmiany w codziennym akademickim funkcjonowaniu. Chiny obecnie rozbudowują infrastrukturę IT, która umożliwi szybszy, łatwiejszy przepływ wiedzy oraz informacji. Pandemia Covid-19 dodatkowo przyspieszyła te procesy i pokazała, że tam, gdzie są trudności, z czasem pojawiają się rozwiązania. W Państwie Środka prowadzi się liczne badania na temat stanu umiędzynarodowienia edukacji w krajach Nowego Pasa i Szlaku (OBOR), bada się możliwości tych krajów, ale także wielu innych, z którymi Chiny planują podjąć współpracę. W moim przekonaniu Chiny szukają partnerów do współpracy oraz umiędzynarodowienia edukacji wyższej, którzy sprostają wymaganiom i narzuconym warunkom. Na koniec warto podkreślić, że proces umiędzynarodowienia edukacji na całym świecie postępuje szybko, a od badaczy z całego świata należy wymagać uważnego przyglądania się temu zjawisku oraz wielokierunkowych analiz. Instytucjonalne badania pomogą wskazać kierunki rozwoju umiędzynarodowienia, a badania nad doświadczeniami edukacyjnymi studentów pozwolą zrozumieć, co tak naprawdę dzieje się w tym systemie. Chiny jako przykład kraju ekspansywnego w rozwiązaniach wymagają szczególnej, wielowymiarowej analizy.

\section{Bibliografia}

Wit H. de, Hunter F., Howard L, Egron-Polak E. (2015). Internationalization of higher education. European Union Parliament Policy Department B: Structural and Cohesion Policies. Dostępny na: http://www.europarl.europa.eu/RegData/etudes/STUD/2015/540370/ IPOL_STU(2015)540370_EN.pdf (otwarty:12.07.2021).

Guo Y., Guo S., Yochim L., Liu X. (2021). Internationalization of Chinese Higher Education: Is It Westernization? „Journal of Studies in International Education”. Dostępny na: https://doi.org/10.1177/1028315321990745 (otwarty:18.07.2021).

Hu M., Willis L.-D. (2016). Towards a Common Transnational Education Framework: Peculiarities in China Matter. „Higher Education Policy”, nr 30 (2), s. 245-261.

Liu B., Liu Q. (2016). Internationalization of Chinese higher education in the era of globalization: Student mobility between China and the globalized world. W: Guo S., Guo Y. (red.). Spotlight on China: Chinese education in the globalized world. Rotterdam: Sense Publishers.

Luke A. (2010). Educating the "other" standpoint and internationalization of higher education. W: Carpentier V., Unterhaler E. (red.). Global inequalities in higher education: Whose interests are you serving? Palgrave: Red Globe Press.

Mańkowska A. (2017). Mobilność edukacyjna chińskich studentów. „Studia z Teorii Wychowania", T. VIII, nr 4 (21), s. 37-54. 
Mańkowska A. (2020). Chiński plan OBOR. Czy Chiny zmienia edukację wyższa na świecie? W: Murawska A., Wiażewicz-Wójtowicz P. (red.). W tyglu zmian. Edukacja akademicka w Polsce i na świecie. Szczecin: Wydawnictwo Naukowe Uniwersytetu Szczecińskiego.

Ng J., Nyland B. (2016). Internationalisation of Higher Education and Global Learning. W: Barkatsas T., Bertram A. (red.). Global Learning in the 21st Century. Rotterdam: Sense Publishers.

OECD Organization for Economic Co-operation and Development (2019). International migration outlook 2019. OECD. Dostępny na: https://www.oecd-ilibrary.org/social-issues-migration-health/international-migration-outlook-2019_c3e35eec-en (otwarty: 17.07.2021).

Qin Y., Alice Y.C. Te. (2016). Cross-Border Higher Education in China: How the Field of Research Has Developed. „Chinese Education \& Society”, nr 49 (4-5), s. 303-323.

Shibao G., Mackie Ch. (2011). Internationalisation of higher education: Integrating international students into Canadian academic environment. „Teaching in Higher Education”, nr 16, s. 305-318.

Stein S., Andreotti V.D.O. (2016). Cash, charity, or competition: International students and the global imaginary. „Higher Education”, nr 72, s. 225-239.

Trahar S. (2015). Learning and Teaching on Transnational Higher Education Programmes in Hong Kong. „Learning and Teaching”, nr 8 (1), s. 95-112.

Wang F., Clarke A., Yu W. (2016). Empty Success or Brilliant Failure: An Analysis of Chinese Students' Study Abroad Experience in a Collaborative Master of Education Programme. „Journal of Studies in International Education”, $\mathrm{nr} 20$ (2), s. 140-163.

Yang H., Lesser B. (2017). Internationalizing the University: A Case Study of A CanadaChina Programme. „Creative Education”, nr 8 (3), s. 359-372.

Yang R. (2016). Internationalization of higher education in China: An overview. W: Guo S., Guo Y. (red.). Spotlight on China: Chinese education in the globalized world. Rotterdam: Sense Publisher.

\title{
PATTERNS AND TRENDS OF INTERNALIZATION IN CHINA'S HIGHER EDUCATION
}

\begin{abstract}
The aim of the article is to discuss patterns and trends of internalization in China's higher education. The article answers the question whether China managed to preserve the local culture in the process of internationalization of education, or perhaps westernization of education dominated these process. The subject of research is the phenomenon of internationalization at higher education stage. Several institutional solutions and practical implications has been described. The article uses existing research by Chinese and foreign authors.
\end{abstract}

Keywords: internalization of education, westernization of education, higher education, China, globalization. 